\title{
Ebola virus disease in pregnancy and anesthetic considerations
}

\author{
J. Sudharma Ranasinghe, Andres Missair, Daria Moaveni, Zahira Zahid, Jennifer Hochman-Cohn \\ Department of Anesthesiology, University of Miami Miller School of Medicine/Jackson Memorial Hospital, Miami, Fl, United \\ Stated
}

Received: March 22, 2015

Accepted: May 28, 2015

Online Published: June 8, 2015

DOI: $10.5430 /$ jha.v4n5p13

URL: http://dx.doi.org/10.5430/jha.v4n5p13

\begin{abstract}
Ebola virus disease (EVD) is often lethal, mortality rates range from $50 \%$ to over $90 \%$, depending on the patient population, viral strain, and access to medical care. During pregnancy, the morbidity and mortality from the viral disease has been suggested to be among the highest of any affected patient population. According to the existing literature, which is confined to a few small case series in Africa, the risk of spontaneous fetal loss is high and there have been no known neonatal survivors. The mode of EVD transmission is well understood and evidence from the current and previous epidemics indicates that transmission can be interrupted by infection control measures. The central element of providing care to a patient suspected of Ebola is a three-step triage process: identify/isolate/inform. Once the diagnosis is confirmed, because of the potentially worse outcomes seen in pregnancy, specialized multidisciplinary care may be needed. In addition, especially in the obstetric setting, there is a high likelihood of exposure to a potentially deadly disease by health care workers. Therefore, these patients should be managed by anesthetic and obstetric providers in centers with expertise, protocols and training. Labor pain management, and the decision to proceed with cesarean delivery or other obstetric interventions will need to be considered on a case-by-case basis, weighing the risks and benefits to the mother, the fetus and the caregivers.
\end{abstract}

Key Words: Ebola virus disease, Pregnancy, Infection control, Airway management, Peripartum period

\section{BACKGROUND}

The 2014 Ebola outbreak ravaging West Africa has made headlines in the lay press and scientific literature due to its unprecedented scale, urban setting, and international spread. The transmission of Ebola virus disease (EVD) to healthcare workers in African field clinics and tertiary hospital centers of various industrialized nations has been the focus of much attention. Another high-risk population, however, has received little coverage by the media. Pregnant patients present specific concerns regarding EVD transmission, dis- ease presentation, mortality, and management. Recently, in a letter to the editor of the Journal of Perinatal Medicine, the authors pleaded for specific clinical recommendations for EVD management in pregnancy. The scarcity of epidemiologic data and published research relevant to the pregnant patient presents serious obstacles to creating evidence-based recommendations. This article aims at reviewing the current knowledge of EVD in pregnancy and presents recommendations on how to manage infected pregnant patients during the peripartum period.

*Correspondence: J. Sudharma Ranasinghe; Email: jranasinghe@med.miami.edu; Address: Department of Anesthesiology, Perioperative Medicine and Pain Management, University of Miami Miller School of Medicine/Jackson Memorial Hospital, 1611 NW 12th Street, Central Building C300. Miami, Fl 33136, United Stated.

Published by Sciedu Press 


\section{Peripartum transmission of Ebola VIRUS}

The transmission of Ebola is by direct contact with blood or body fluids of an infected symptomatic person, including saliva, amniotic fluid, vaginal secretions, vomit, urine, stool, sweat, and breast milk. ${ }^{[1]}$ Ebola virus is most frequently found in the saliva of a patient in the acute phase of illness (see Table 1). The incubation period of the disease ranges from 2 to 21 days. Ebola virus has been detected in amniotic fluid and breast milk samples during both the acute and convalescence phases of the illness (see Table 1). Therefore, breast feeding is not recommended when alternative forms of neonatal nutrition are available, ${ }^{[2,3]}$ and both vaginal and cesarean delivery may expose healthcare providers to large amounts of infectious body fluids.

Table 1. Ebola virus detection by reverse-transcription polymerase chain reaction (RCT-PCR) in body fluids collected from EVD patients during an outbreak in Gulu, Uganda and the maximum described persistence after symptom onset described in the literature

\begin{tabular}{|c|c|c|c|}
\hline \multirow{2}{*}{ Body Fluid } & Acute Phase of Illness & Convalescent Phase of Illness & \multirow{2}{*}{$\begin{array}{l}\text { Last day detected after } \\
\text { symptom onset described } \\
\text { in the literature }\end{array}$} \\
\hline & Number detected/mumber tested(\%) & Number detected/mumber tested(\%) & \\
\hline Skin & $1 / 8(13 \%)$ & $0 / 4(0 \%)$ & 6 \\
\hline Saliva & $8 / 12(67 \%)$ & $0 / 4(0 \%)$ & 8 \\
\hline Urime & $0 / 7(0 \%)$ & $0 / 4(0 \%)$ & 23 \\
\hline Stool/Feces & $2 / 4(50 \%)$ & $\mathrm{n} / \mathrm{d}$ & 29 \\
\hline Breast milk & $1 / 1(100 \%)$ & $1 / 1(100 \%)$ & 15 \\
\hline Semen & $\mathrm{n} / \mathrm{d}$ & $1 / 2(50 \%)$ & 101 \\
\hline Vaginal Fluid & $\mathrm{n} / \mathrm{d}$ & $\mathrm{n} / \mathrm{d}$ & 33 \\
\hline
\end{tabular}

Note. $\mathrm{n} / \mathrm{d}=$ not done on specimens from the EVD outbreak in Gulu, Uganda. ${ }^{[1]}$

\section{EVD IN PREGNANCY: EPIDEMIOLOGIC DATA AND ANALYSIS}

There is no evidence from previous outbreaks that pregnant women are more susceptible to EVD. ${ }^{[4]}$ However, it appears that pregnant women are more likely to have severe complications and fatal disease than non-pregnant individuals. ${ }^{[4]}$ Only two major outbreaks (the 1976 Yambuku and 1996 Kikwit epidemics in the Democratic Republic of Congo) have reported epidemiologic data on pregnant EVD cases. ${ }^{[5]}$

During the 1976 outbreak, 318 confirmed cases of EVD were reported. A disproportionate number of pregnant patients were identified ( $46 \%$ of 177 women) due to receipt of prenatal vitamin injections infected with Ebola virus. Overall mortality $(88 \%)$ was comparable to mortality among pregnant women $(89 \%)$. Of the 82 pregnant patients, $23 \%$ suffered spontaneous abortions in the first or second trimesters. All neonates born to EVD patients died within 19 days of birth. ${ }^{[4]}$ During the 1996 outbreak in Kikwit, Democratic Republic of Congo, 105 women were confirmed with EVD, of which 15 were pregnant. All of the pregnant women developed vaginal and uterine bleeding (see Table 2), and 14 of 15 (93\%), died within 10 days of illness onset compared to $70 \%$ of non-pregnant women during the same epidemic. All of the pregnancies $(100 \%)$ resulted in fetal or neonatal loss. Only one woman delivered a full term baby, and this baby developed fever and died 3 days later. ${ }^{[6]}$

The pooled estimate analysis of these two outbreaks yields a statistically significant increase in mortality among pregnant patients with EVD (see Table 3). Using a one-tailed Fisher's exact test, the mortality rate of pregnant women versus the general population is $90 \%$ versus $82 \%$ ( $p=.03$, GraphPad QuickCalcs). Interestingly, this result was found regardless of Ebola strain lethality, which can range between $50 \%$, as in the current outbreak, and $88 \%$, seen with the Zaire strain. When compared to epidemiologic data from the Kikwit General Hospital for the 1996 outbreak, where the mortality rate of non-pregnant women was reported to be $70 \%$ (28/40), the calculated mortality for pregnant women (90\%) suggests that pregnancy may be an independent risk factor for EVD-associated death.

As seen with other hemorrhagic infections, such as Lassa fever, spontaneous abortion appears to be frequent among pregnant women with EVD. ${ }^{[6,7]}$ This may be caused by pyrexia, intravascular coagulopathy, and Ebola infection transmitted to the fetus. Converse to Lassa fever, however, evacuation of uterine contents does not improve mortality in EVD patients. ${ }^{[4,6]}$ In fact, the mortality of pregnant women 
with EVD remained unchanged throughout all trimesters of pregnancy during the 1996 Kikwit outbreak.

Table 2. The signs and symptoms of the pregnant patients during 1996 EVD outbreak in Kikwit ${ }^{[6]}$

\begin{tabular}{ll}
\hline Signs and Symptoms EHF & Prevalence (\%) \\
\hline Fever & 100 \\
Asthenia & 100 \\
Abdominal pain & 100 \\
Conjunctivitis & 100 \\
Anorexia & 100 \\
Diarrhea & 100 \\
Hiccups & 100 \\
Arthralgia & 100 \\
Shock & 100 \\
Dysphagia & 100 \\
Nausea & 87 \\
Increased respiratory rate & 73 \\
Vomiting & 60 \\
Retrosternal pain & 46 \\
Cutaneous eruption & 13 \\
Signs of hemorrhage at presentation & \\
Severe genital bleeding & 100 \\
Melena & 67 \\
Gum Bleeding & 53 \\
Ecchymosis & 47 \\
Bleeding at injection sites & 47 \\
Hematemesis & 40 \\
Petechiae & 13 \\
Hematuria & 7 \\
Neuropsychiatric symptoms & 100 \\
Headache & 100 \\
Anxiety & 93 \\
Decreased consciousness & 93 \\
Apathy & \\
Coma & \\
Delirium & \\
Convulsions & 100 \\
\hline
\end{tabular}

\section{Potential anesthetic management IMPLICATIONS}

\subsection{General considerations}

According to the ACOG advisory, in a fulminant case of EVD with extremely poor prognosis for both mother and baby, "it may be prudent to avoid usual obstetric interventions such as fetal monitoring, cesarean delivery, induction of labor, or surgical repair of lacerations." This helps to protect the medical staff from highly infectious exposures. ${ }^{[2,3]}$ Surgery, especially in women with hemorrhagic manifestations, could compromise maternal health even in highly resourced settings like the United States. ${ }^{[3]}$

Published by Sciedu Press
At present, it is not known how best to treat women with "early stage" EVD and obstetric interventions will need to be considered based on the risks and benefits to the mother, fetus and caregivers. ${ }^{[3,8,9]}$ It is not known whether treatment and intervention at early stages of the disease result in a better prognosis for the patient and fetus. ${ }^{[3,10,11]}$

Table 3. Pooled epidemiologic data on pregnant EVD cases

\begin{tabular}{lll}
\hline Raw Data & 1976 Yambuku & 1996 Kikwit \\
\hline Deaths pregnant EVD patients & 73 & 14 \\
Total pregnant EVD patients & 82 & 15 \\
Deaths Total EVD & 280 & 245 \\
Total Female EVD cases & 177 & 105 \\
Total EVD cases & 318 & 316 \\
& & Overall Patient \\
Pooled Results & Peripartum & Mortality (includes \\
& Mortality & pregnant patients) \\
& 87 & 438 \\
EVD & 97 & 537 \\
\hline
\end{tabular}

Currently, there are no approved antiviral treatments or vaccines available for Ebola virus infection. Several antiviral medications for EBV are in development and Phase I trials are underway for some vaccine candidates. ${ }^{[12]}$ Therefore, prevention of spread of the disease remains particularly important.

Although specific evidence is lacking, the higher incidence of fetal demise may suggest an increased risk for unplanned cesarean delivery in the hospitalized setting. This decision should be tempered by the poor prognosis of EVD neonates, and the increased risk of healthcare provider exposure in the operative setting. Anticipated complications from EVD that may require emergent anesthetic management include: retained products of conception following spontaneous abortion, postpartum hemorrhage, bleeding genital lacerations, seizures, and coma. Clinical management should focus on supportive care of complications, such as hypovolemia, electrolyte abnormalities, hematologic abnormalities, refractory shock, hypoxia, hemorrhage, septic shock, multi-organ failure, and DIC. ${ }^{[6,13]}$ Broad spectrum antibiotics are suggested especially with evidence of septic shock. ${ }^{[13]}$

Use of a massive transfusion protocol may be necessary, especially if the patient presents with antepartum or postpartum hemorrhage. Although the mortality rate for pregnant women has been greater than $90 \%,{ }^{[6,14]}$ the resources in the United States (rapid infuser, large blood banks), could increase the survival rate of pregnant patients with Ebola. However, these interventions should be considered on a case by case basis as discussed already. 


\subsection{Management of labor analgesia}

Although neuraxial labor analgesia is the most effective and least depressant method of labor pain relief, ${ }^{[15]}$ this technique is likely contraindicated in EVD due to the high risk of coagulopathy. There is no data on obstetric outcomes from settings with highly developed healthcare systems. According to the existing literature, which is confined to small case series in Africa (low resource settings) there is no information on providing labor analgesia in women with EVD. In addition, invasive procedures should be kept to a minimum in these patients to avoid risk of body fluid exposure and sharps injury. Therefore, less invasive methods of analgesia, such as systemic opioid analgesia, ${ }^{[16]}$ likely pose less risk to both the patient and provider.

\subsection{Airway management}

In the event that cesarean delivery is required, general anesthesia is most likely indicated due to the hemorrhagic pathophysiology of the disease. ${ }^{[14,17,18]}$ Proper Personal Protective Equipment (PPE) must be donned by all healthcare workers in the operating room. ${ }^{[19,20]}$ The American Society of Anesthesiology (ASA) Ebola Workgroup has provided recommendations regarding the proper management of any patient with Ebola requiring tracheal intubation and surgery: ${ }^{[21]}$

- Anesthesia providers should not attempt emergency intubations or procedures until properly donned in PPE. This necessitates significant time. The ASA recommends "full PPE precautions are to be adhered to regardless of an emergency status or acute deterioration in patient status".

- Enhanced precaution PPE is advised when it is anticipated that the healthcare worker may be exposed to aerosol generating procedures such as intubation, extubation, airway suction, Continuous Positive Airway
Preassure (CPAP), Bilevel Positive Airway Pressure (BiPAP), surgery and usage of electrocautery. The $\mathrm{CDC}$ recommends that any aerosol-generating procedure should be performed in an Airborne Infection Isolation Room when feasible. ${ }^{[22]}$

- Every effort should be made to keep the patient in her own isolation room and moving anesthesia and surgical equipment to the bedside. Patient recovery also should occur in the operating room or patient's room.

- The anesthesia machine should be emptied and stocked with only essential supplies and anticipated medications. Once a patient enters the operating room, or the anesthesiologist enters the patient's room with the anesthesia machine, additional supplies, equipment and medications may be unavailable. Anesthesiologist should remain in the room for the entire duration of the case and avoid handovers.

\section{Conclusion}

In conclusion, although the chance of EBV spread in the United States or caring for pregnant patients with the disease is extremely small, it is important to be aware of the inherent risks associated with the care of these patients due to the high likelihood of exposure to a potentially deadly disease in the obstetric setting. Based on our analysis of the limited epidemiologic data, pregnancy significantly increases the risk of mortality in EVD patients. Given the small sample size, however, additional data from the current epidemic is needed to confirm this finding. Currently, there are no specific clinical recommendations for EVD management in pregnancy. However, anticipation of the hemorrhagic complications associated with and exacerbated by pregnancy may provide a narrow window of opportunity to treat these patients using a risk-benefit analysis of established interventions.

\section{REFERENCES}

[1] Centers for Disease Control and Prevention. Review of Human-toHuman Transmission of Ebola Virus. [cited 2014 Nov 2]. Available from: http://www.cdc.gov/vhf/ebola/transmission /human-transmission.html

[2] Caluwaerts S, Lagrou D, Van Herp M, et al. Guidance paper Ebola Treatment Center (ETC): pregnant and lactating women. Brussels: Médecins Sans Frontières. 2014. Available from: https://www.rcog.org.uk/globalassets/documents /news/etc-preg-guidance-paper.pdf

[3] American Congress of Obstetricians and Gynecologists. Practice Advisory: Care of Obstetric Patients During an Ebola Virus Outbreak. 2014. Available from: http://www . acog.org

[4] Jamieson DJ, Uyeki TM, Callaghan WM, et al. What ObstetricianGynecologists should know about Ebola: A Perspective from the
Centers of Disease Control and Prevention. Obstet.Gynecol. 2014; 124: 1005-10. PMid: 25203368. http://dx.doi.org/10.1097 /AOG.0000000000000533

[5] Feldmann H1, Geisbert TW. Ebola haemorrhagic fever. Lancet. 2011 March 5; 377(9768): 849-62. http://dx.doi.org/10.1016/S01 40-6736(10)60667-8

[6] Muppa K, Mukundu W, Bwaka MA, et al. Ebola hemorrhagic fever and pregnancy. J of infect disease. 1999 Feb; 179 (suppl1): S11-S12. PMid: 9988157. http://dx.doi.org/10.1086/514289

[7] World Health Organization, Ebola hemorrhagic fever in Zaire, 1976. Bull World Health Organ. 1978; 56: 271-93. PMid: 307456.

[8] Centers for Disease Control and Prevention. Evaaluating Patients for possible Ebola Virua Disease: Recommendation for Healthcare Personnel and Health Officials. [cited 2014 Nov 2]. Ava- 
iable from: http://www.cdc.gov/vhf/ebola/pdf/ed-algor ithm-management-patients-possible-ebola.pdf

[9] Centers for Disease Control and Prevention. Ebola Virus Disease, Algorithm for Evaluation of the Returned Traveler. [cited 2014 Nov 2]. Avaiable from: http://www.nndoh.org/pdf/phep/evaluat ion_transportation_contact_tracing.pdf

[10] Centers for Disease Control and Prevention. Interim Guidance for Specimen Collection, Transport, Testing, and Submission for Patients with Suspected Infection with Ebola Virus Infection. [cited 2014 Nov 2]. Available from: http://www.cdc.gov/vhf/ebola/pdf/eb ola-lab-guidance.pdf

[11] Centers for Disease Control and Prevention. How U.S. Clinical Laboratories Can Safely Manage Specimens from Persons Under Investigation for Ebola Virus Disease. [cited 2014 Nov 2]. Available from: http://www.cdc.gov/vhf/ebola/pdf/ebola-lab-gui dance.pdf

[12] Centers for Disease Control and Prevention. Questions and Answers on Experimental Treatments and Vaccines for Ebola. [cited 2014 Nov 2]. Available from: http://www.cdc.gov/vhf/ebola/outbreaks/2014-wes t-africa/qa-experimental-treatments.html

[13] Kreuels B, Wichmann D, Emmerich P, et al. A case of Severe Ebola Virus Infection Complicated by Gram-Negative Septicemia. N Engl J Med. 2014 Dec; 371: 2394-2401. PMid: 25337633. http://dx.doi.org/10.1056/NEJMoa1411677

[14] Centers for Disease Control and Prevention. CDC information for Health Care Workers. [cited 2014 Nov 2]. Available from: http: //www.cdc.gov/vhf/ebola/hcp/index.html

[15] American Congress of Obstetricians and Gynecologists (ACOG) Committee Opinion \#295 pain relief during labor. Obstet Gynecol. 2004; 104: 213. PMid: 15229040. http://dx.doi.org/10.1097 /00006250-200407000-00061
[16] Liu ZQ, Chen XB, Li HB, et al. A comparison of remifentanil parturient-controlled intravenous analgesia with epidural analgesia: a meta-analysis of randomized controlled trials. Anesth Analg. 2014; 118: 598-603. PMid: 24557106. http://dx.doi.org/10.1213 /ANE. 0000000000000077

[17] Ansari AA. Clinical features and pathobiology of Ebola virus infection. J Autoimmun. 2014 Dec; 55: 1-9. PMid: 25260583. http: //dx.doi.org/10.1186/1478-4505-9-20

[18] Centers for Disease Control and Prevention. CDC Main Ebola Page. [cited 2014 Nov 2]. Available from: http://www.cdc.gov/vhf / ebola/

[19] Centers for Disease Control and Prevention. Guidance on Personal Protective Equipment To Be Used by Healthcare Workers During Management of Patients with Ebola Virus Disease in U.S. Hospitals, Including Procedures for Putting On (Donning) and Removing (Doffing). [cited 2014 Nov 2]. Available from: http://www.cdc.gov/ vhf/ebola/hcp/procedures-for-ppe.html

[20] World Health Organization. Personal Protective Equipment in the Context of Filovirus Disease Outbreak Response. Rapid advice guideline. Summary of the recommendations. [cited 2014 Nov 2]. Available from: http://apps. who.int/iris/bitstream/1066 5/137410/1/WHO_EVD_Guidance_PPE_14.1_eng.pdf?ua=1

[21] American Society of Anesthesiology. Recommendations From the ASA Ebola Workgroup. 2014. Available from: https : //www . asah q.org/For-Members/Clinical-Information/Ebola

[22] Centers for Disease Control and Prevention. Infection Prevention and Control Recommendations for Hospitalized Patients with Known or Suspected Ebola Virus Disease in U.S. Hospitals. [cited 2014 Nov 2]. Available from: http://www.cdc.gov/vhf/ebola/hcp/infect ion-prevention-and-control-recommendations.html 